\title{
EL OTRO LARRA: LUIS MARIANO DE LARRA Y WETORET, DRAMATURGO 'DESCONOCIDO' DE LA SEGUNDA MITAD DEL SIGLO XIX (CON APÉNDICE DE TÍTULOS)
}

\author{
David T. GIES \\ University of Virginia
}

Emplear el adjetivo «desconocido» para calificar a una de las figuras literarias más aplaudidas de su época puede ser arriesgado, si no totalmente desquiciado. ¿Cómo puede incluirse el nombre del autor de la famosísima zarzuela El barberillo de Lavapiés entre la nómina de autores que constituyen el tema de este número especial de Anales de Literatura Española? ¿Cómo sugerir que un autor que lleva uno de los apellidos más reconocibles del siglo XIX -Larra- sea «desconocido»? Pero a pesar de su apellido, a pesar de la larga lista de sus dramas estrenados y publicados en la segunda mitad del siglo, y a pesar de su colaboración con otros dramaturgos recordados hoy en día, Luis Mariano de Larra y Wetoret (18301901) ha sido sepultado en el más profundo olvido literario y biográfico. Sorprende (pero quizás, no tanto) la ausencia de estudios sobre su obra ${ }^{1}$; es más: sorprende la falta de mención de su obra en libros dedicados a la historia del teatro español. ${ }^{2}$ Por haber ganado mucha fama en el mundo de

1. No hay ni una sola mención de Mariano José de Larra en M.A. Rees, The Nineteenth-Century Theatre in Spain: A Bibliography of Criticism and Documentation, lo que indica la falta de estudios sobre su obra; José Luis González Subías recoge tres entradas -una reseña de El barberillo de Lavapés, una edición de la misma y un capítulo en una historia del teatro decimónonico-en su Catálogo de estudios sobre el teatro romántico español. Gies incluye algunas páginas sobre Larra hijo en su El teatro en la España del siglo XIX.

2. Por ejemplo, hay una sola mención de Luis Mariano de Larra en la Historia del teatro español, ed. Javier Huerta Calvo (II: 1966). 
la zarzuela, los libros dedicados a este género no pueden evitar incluir su nombre en el elenco de autores comentados, pero tales menciones suelen ser someras y sin interés crítico. Larra hijo no es, ni mucho menos, el mejor dramaturgo de la época y por eso quizás se comprende el olvido (aunque no será Larra el único dramaturgo decimonónico injustamente consignado al olvido), porque sabemos muy poco de él. No existen estudios de sus obras teatrales ni carteleras completas de su producción dramática ni apuntes biográficos que nos puedan orientar. No existe un catálogo fiable de todas sus obras. Esto dicho, no pretendo aquí ofrecer una relación completa de su vida y obra, pero sí quisiera llamar un poco la atención sobre una figura que merece ser más apreciada y estudiada.

El siguiente párrafo, escrito por Gonzalo Calvo Asensio en 1875, sintetiza perfectamente los logros de Larra como poeta dramático (aunque más adelante Calvo Asensio comentará sus muchos defectos):

\begin{abstract}
Reune este laborioso escritor cuantas condiciones exijirse pueden a un autor dramático. Inventiva, discreción, galanura, facilidad y abundante vena como pocos, entonación robusta, siempre que el asunto lo requiere, así como también gracia chispeante y naturalidad cómica. Domina todos los géneros, versifica con una espontaneidad y una fluidez admirables, y conoce los secretos de la escena como quizás sólo Vega los conocía. Dialoga con soltura, mantiene el interés con multitud de recursos ingeniosos, si no todos del mejor gusto, siempre muy del agrado público, testimoniando sus grandes facultades para el teatro, y por escepción y rarísima vez deja de conquistar el aplauso. Según en el lenguaje de los del oficio se dice, planea con suma facilidad, y con facilidad aun mayor viste con espléndido ropaje su pensamiento. Distínguese lo mismo en el drama que en la comedia, y así triunfa en la zarzuela, como desciende al sainete o la magia, valiéndose de la prosa y del verso indistintamente y variando de tono y usando de diversos registros, según las artísticas conveniencias lo demandan (128-129).
\end{abstract}

Aunque su «fama» vino más bien de su labor como dramaturgo y libretista de zarzuelas, muchas veces en colaboración con otras figuras literarias, también publicó varias novelas originales (Tres noches de amor y celos; La gota de tinta, 1858; La última sonrisa, 1891; Si yo fuera rico, 1896), traducciones del francés (El libro de las mujeres) y poesías. Una búsqueda nada científica ${ }^{3}$

3. Estos títulos se han encontrado en varias fuentes, entre ellas: la cartelera de Vallejo y Ojeda; Veinticuatro Diarios; el Catálogo de obras de la Fundación Juan March; Rogers; las contraportadas de obras de Larra publicadas; y los catálogos de varias bibliotecas. Varias fuentes confunden sus obras con las del actor y dramaturgo Luis de Larra y Osorio. Le agradezco a mi amigo y colega José Luis González Subías las adiciones y correcciones al Apénice. Se invita a los lectores a mandar más noticias o correcciones a dtg@ virginia.edu. 
produce una lista de unos cien títulos dramáticos (ver el Apéndice de títu$\operatorname{los}){ }^{4}$

Esta larga y parcial lista de títulos sólo sugiere en parte la enorme actividad literaria de Luis Mariano de Larra. Muchas de estas obras son zarzuelas, cuya música fue producida por Oudrid, Barbieri, Caballero, Gaztambide o Arrieta (es decir, por los grandes maestros de la zarzuela española en la segunda mitad del siglo) y otras fueron escritas en colaboración con dramaturgos como Ventura de la Vega (Barómetro conyugal), Ramón de Navarrete (Cadenas de oro), Antonio García Gutiérrez (El conde y el condenado), Narciso Serra (Los infieles) o Luis de Eguílaz (Entre todas las mujeres, Sapos y culebras, Una virgen de Murillo). Muchos títulos llegaron a publicarse en una segunda, tercera, cuarta, quinta, octava ( $L a$ oración de la tarde) o, en el caso excepcional de El barberillo de Lavapiés, undécima edición.

Como este breve estudio no puede aspirar a ser completo, comentaré dos de las obras más paradigmáticas la época juvenil del autor, Una virgen de Murillo (1854) y La oración de la tarde (1858). La primera, escrita en colaboración con otro dramaturgo «olvidado» de mediados del siglo, Luis de Eguílaz, se estrenó el 24 de diciembre de 1854 en el Teatro Variedades (uno de los teatros que favoreció sus producciones) y gozó de un éxito típico de la temporada de Navidades: estuvo en cartelera desde el día 24 hasta el día 7 de enero de 1855. Durante los primeros cinco días alternó (tarde y noche) con otra obra del mismo autor titulada Entre todas las mujeres. ${ }^{5}$ Luego, volvió a las tablas en 1856 y 1864. La segunda obra, La oración de la tarde, estrenada en el Teatro del Circo en noviembre de 1858, llegó a ser uno de sus dramas más representados. Después de casi dos semanas seguidas (desde el 26 de noviembre hasta el 14 de diciembre), volvió a representarse en enero, marzo y mayo de 1859 y luego volvió a verse en varios teatros madrileños (Variedades, Olimpo) en los años 1860 1861, 1862 y 1863.

Volvamos a La virgen de Murillo. Esta obra, «representada por primera vez con estraordinario éxito el día 24 de diciembre de 1854» (según reza la portada, con la retórica ya típica -pero en este caso acertada, porque gozó de 16 representaciones seguidas- de la época), se sitúa en Sevilla en el año «163...». Eguílaz y Larra captan elementos de la historia del drama español al presentar una comedia de capa y espada cuyos elementos incluyen un

\footnotetext{
4. En un artículo titulado «La situación del autor dramático,» publicado en La Época el 8 de mayo de 1882, Larra («ya viejo en el oficio de escribir comedias») confiesa haber escrito noventa obras dramáticas.

5. Ver la Cartelera de Vallejo y Ojeda.
} 
amor no requerido, confusión de identidades, disfraces, mentiras, cartas, secretos y una acción que se resuelve (¿cómo no?) felizmente al final. Son dos las cosas que podemos considerar originales, o por lo menos, de notable interés, en la obra. Una es la presencia del Santo Oficio, tema ya nada prohibido en la dramaturgia decimonónica (la Inquisición había sido disuelta en 1834) y la otra el escenario especialmente innovador del segundo acto. Que Larra conoce la historia teatral queda fuera de duda cuando el público oye ecos del Don Juan Tenorio de Zorrilla ya en la primera larga intervención de don Alonso:

Pero hace el amor milagros;

y amor y celos me acosan:

y bajara yo, no digo

a esta alameda frondosa, sino al infierno a buscar al ángel que me enamora. (Acto I, Escena 1)

referencia que se confirma en seguida cuando pregunta: ¿Puedes tú creer, Chinchilla, que rindiendo el alma toda don Alonso Pimentel, el coco de las hermosas, el cuco de las gallegas, y el Juan Tenorio de todas, le desprecie una andaluza con ceño adusto y faz torva? (I, 1)

Pero el Tenorio no será ni tema de inspiración ni de parodia (aunque, como sabemos, va a ser exactamente eso durante toda la segunda mitad del siglo ${ }^{6}$ ) porque Larra tiene más interés en crear una obra entretenida, rápida y bien versificada. La fuente más directa de Una virgen de Murillo es Calderón; lo que escribe Larra es una versión modernizada de $L a$ dama duende (1629), cosa que reconoce el crítico de La Época al llamarla «imitación de nuestro teatro antiguo» (27 de diciembre de 1854). Esta fusión de lo contemporáneo con lo antiguo le gana a Larra la admiración del público (tanto por esta obra como por muchas otras que escribirá a lo largo de su vida) y el autor se muestra consciente de sus préstamos de la historia literaria española. En un momento dado de la obra, don Alonso,

6. Jeffrey T. Bersett, El burlado de Sevilla: Nineteenth-Century Theatrical Appropriations of Don Juan Tenorio. Newark, DE: Juan de la Cuesta Press, 2003. 
con evidente orgullo por sus conocimientos literarios, recita los siguientes versos:

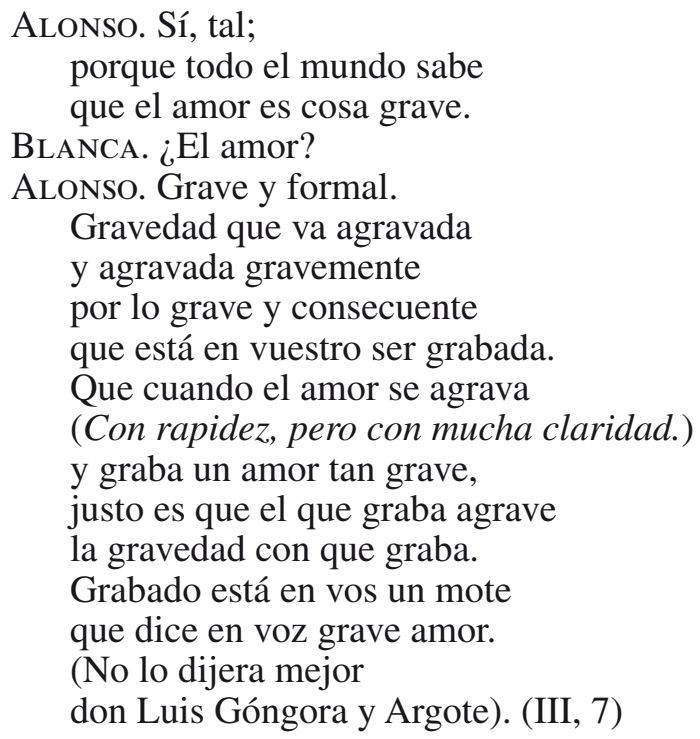

Tal afectación artística (en un momento divertidamente metapoética) no quita encanto a la obra a pesar de la falta de sutileza. ${ }^{7}$ Curiosamente, un tema que se espera -la pintura de Murillo- tiene poca resonancia en esta obra; Larra no lo desarrolla como era de esperar, dejando en el tintero cualquiera meditación sobre el arte de la pintura, el oficio del pintor, o los éxitos de Murillo. Sólo una vez el mismo pintor elabora su parecer sobre lo que es ser artista, pero lo que dice son tópicos sin profundidad:

La independencia del alma es lo que engrandece al arte. Nacer solo y sin fortuna, vivir del mundo olvidado, en un rincón ignorado sin oro, sin noble cuna; trabajar con fé creciente

7. Hay otra referencia a Quevedo cuando Quiñones, la dueña -representada por Concepción Rodríguez, la mujer del famoso impresario Juan de Grimaldi-, dice «Si alguien chilla / tachándome de indiscreta, / diré lo que aquel poeta: / 'Poderoso caballero / es don dinero.'» 


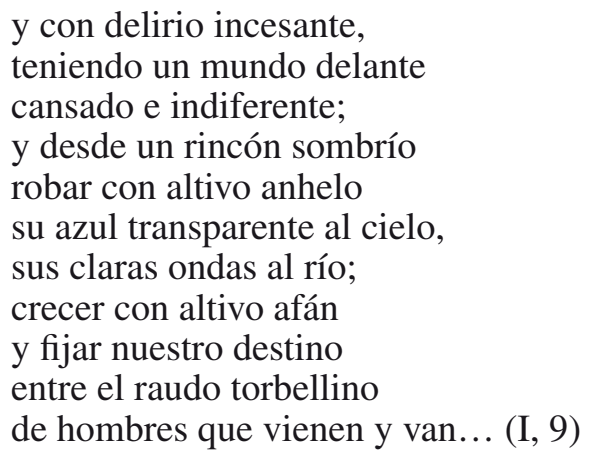

A pesar de la observación de Blanca de que «Murillo es más [que un hidalgo], es pintor» (II, 2), sólo la referencia al «azul transparente» se nos acerca al mundo artístico de Bartolomé Murillo, cuyos retratos de la Virgen le ganaron la máxima fama. Y son estas mismas vírgenes retratadas por Murillo las que sirven como fulcro del argumento del drama de Larra. El pintor, enamorado de una misteriosa dama, al pintar sus retratos siempre pinta la cara de esta «duende,» acaso sin desear hacerlo: «Siempre ese rostro cruel / brota en mis lienzos sutil / a mi pesar» (II, 11). Cuando Murillo, frustrado por el amor sin corresponder que siente, rompe uno de los cuadros, Alonso, su rival por la mano de Blanca, le denuncia a la Inquisición («iEs caso de la inquisición! / ¡La santa Virgen ha roto!») (II, 12).

Larra cuida mucho el escenario, es decir, conceptualiza bien los espacios de sus dramas. El Acto Segundo de La virgen de Murillo es especialmente interesante, porque propone un escenario dividido en espacios bien definidos y en los que distintas acciones tienen lugar simultaneamente. La cita es larga, pero así lo describe el autor:

El teatro dividido en tres partes. La de la derecha es una habitación de una casa muy antigua, pero lujosamente decorada; puerta al foro y a la derecha; un balcón en la izquierda con antepecho de balaustres de piedra; una mesa y varios taburetes. En la parte del centro se verá en primer término el caballete de una tapia, y detrás de éste varias copas de árboles. Se supone que esta parte es un jardín que está a nivel de la planta baja de las dos casas que ocupan lo demás del escenario. El foro de tejados, y en último término los últimos cuerpos de la Giralda. La fachada de la parte de la derecha que da al jardín será de piedra oscura: la de la izquierda blanca, dejando ver por algunos desconchones la fábrica de ladrillo. La parte de la izquierda es una habitación toda blanca y pobremente amueblada. Puerta al foro; otra a la izquierda en segundo término, y a la derecha dos ventanas de antepecho. Frente a la primera ventana y casi de espaldas al público un caballete con un cuadro a medio pintar junto a la segunda ventana una mesa; sobre ella una caja 
de colores, paleta y pinceles: varios cuadros sin marco colgados por las paredes sin simetría: por la puerta del foro se ve la escalera que conduce al piso bajo de la posada: una espada colgada en un lado, en otro una capa; sobre los taburetes libros, ropa y papeles. Puertas vidrieras en el balcón de la derecha: en las ventanas de la izquierda puertas con lienzo en vez de vidrios. La parte de la derecha y la del centro a oscuras: la de la izquierda alumbrada por una vela que arderá en un candelero colocado sobre la mesa. Al levantarse el telón aparecen en la habitación de la izquierda Celia e Inés limpiando los muebles y colocándolos con orden.

Color, luz, iluminación, equilibrio, materia (ladrillo, piedra): es una descripción digna de un Mesonero Romanos o un Galdós, de un cuadro de costumbres o de una novela realista. Y el dramaturgo integra esos espacios en la acción de la obra, usando bien los tres planos para complicar el argumento, revelar detalles de los personajes y mover la acción hacia su lógico desenlace (II, 12 ofrece un buen ejemplo).

La oración de la tarde, estrenada tres años después del éxito de $L a$ virgen de Murillo, presenta un tema archiconocido, pero escrito con un toque original. Recurriendo al tema de la huérfana abandonada (que es, por ejemplo, el tema del conocido melodrama de Juan de Grimaldi, La huérfana de Bruselas, que se había representado en España más de 150 veces desde su estreno en 1825, e includo en el mismo año 1858), Larra envuelve la figura de la pobre niña desamparada en un mundo religioso. Es decir, para María, «la única [madre] que conocí» es la Virgen María $(I, 8)$. Este concepto abre la obra a una serie de consideraciones de tipo religioso similares a lo que Gertrudis Gómez de Avellaneda elabora en Baltasar (estrenado el mismo año de 1858). Es una obra que capta perfectamente la ideología dominante de la burguesía española de mediados del siglo: María piensa que la única forma de ganar el honor, el respeto, la protección y el «nombre» que ha perdido por su condición de huérfana es casarse. Sólo el matrimonio le brindará aquellos valores necesarios para defenderse ante la sociedad. Es una obra de capa y espada (honor, amor, venganza) con una superposición de religión y maternalismo. Larra situa la obra en el siglo XVIII, pero sin profundizar en la política o la filosofía de dicho siglo; se menciona a Felipe $\mathrm{V}$ una sola vez, sin ninguna integración de lo que sería una ideología ilustrada en las preocupaciones del medio siglo decimonónico. Las fechas que se mencionan en la comedia son el 14 y 15 de agosto de 1718 (la Fiesta de la Virgen); sin embargo, podría haberse localizado en cualquier siglo.

Aunque la descripción del escenario en esta obra no llega al nivel detallado de La virgen de Murillo, Larra sigue demostrando su interés en un «realismo» teatral en la primera acotación: 
Casa pobre. Muebles antiguos y modestos. Dos puertas laterales, una en el foro, que da a la calle del pueblo, y a cuyos dos lados hay dos ventanas bajas con rejas que dan al exterior: estas y aquella con puertas grandes que cierren por dentro. A la izquierda una mesa grande de nogal: un sillón grande de baqueta y varios taburetes. Algunos cuadros en las paredes.

La escena del segundo acto es aún más detallada (no la reproducimos aquí), y en ella se nota un control del espacio, de la estructura arquitectónica del sitio y de la iluminación.

El detalle religioso es la clave de la obra. En su dedicatoria («a mi hijo»), Larra confiesa su «intención religiosa»:

Ignoro, vida mía, el éxito que tendrá este drama, uno de los que más he pensado y sentido: pero casi me atrevo a esperar que será bueno, llevando al frente de sus versos la sonrisa de un ángel. En él se enaltece el PERDÓN DE LAS INJURIAS, y su intención religiosa disculpará sin duda sus errores literarios. Tu padre, que como tu ilustre abuelo, el inolvidable Fígaro, no ha tenido pocas que perdonar en su corta carrera de escritor público, sólo quiere que cuando puedas leerle, encierres en tu alma cristiana el tesoro de la religión, fuente de todo bien; y iojalá cuando cruces el áspero camino de la vida y tu padre no te preste ya en el mundo la sombra de su cariño, te acuerdes de rezar siempre por su memoria la ORACIÓN DE LA TARDE! (mayúsculas en el original)

Cuando María por fin se encuentra amada (por D. Gonzalo), la da gracias a la Madre de Dios:
¡Ah! ¡gracias, gracias, Señor!...
al fin ... al fin soy amada, al fin una mano amiga
podrá ya enjugar mis lágrimas.
¡Ya no estoy sola en el mundo
como hace un instante estaba!
Si no es su pasión engaño, si son ciertas sus palabras, fálteme la luz del día
si la de su amor me falta!
¡Tú, Madre de Dios, la única
que conocí en mi desgracias,
vierte un rayo de ventura
en mi vida solitaria
que aliento preste a mi espíritu, 
que fecundice mi alma, que enjugue mis tristes párpados...

o me los cierre mañana! (I, 8)

Varias veces recurre a citas bíblicas para subrayar los múltiples temas de la obra (que sólo el matrimonio puede ofrecer el honor y respeto que necesita una mujer, que el perdón debe triunfar sobre la venganza y el odio, etc.). Insiste Margarita, leyendo de la Biblia, al final: «Cuando os pusiereis a orar, si tenéis algún odio contra alguno, perdonadle, para que vuestro Padre, que está en los cielos, os perdone también a vosotros vuestros pecados...» (III, 10). Este recurso, visto como «altamente católico» (La Discusión 23 diciembre 1858), fue cuestionado por el crítico que le acusa a Larra de olvidarse «de que el catolicismo prohibe la lectura de los libros sagrados.» Pero al final, en medio de altas tensiones entre D. Gonzalo y D. Diego, ella sigue rezando, oraciones que funcionan como bálsamo en las almas de los dos antagonistas. D. Diego, pensando en las madres de María y de Margarita, concluye:

Que si fueron sus acciones causa de perpétuo llanto, siempre el perdón es más anto concedido entre oraciones. Rezad con fervor y anhelo para que a su puerto arriben, ¡la oración de los que viven abre a los muertos el cielo! (III, 10)

Larra falla en su intento de crear el personaje de Margarita, la huérfana de 11 años. Aunque es una niña joven, habla com una mujer adulta, es mandona, demasiado astuta y locuaz. El diálogo que tiene con María, por ejemplo, en I, 4, sugiere una consciencia mucho más madura que la de una niña. Escuchémosla:

¿Aun no te das por vencida?...

¡Voy a pintarte tu vida,

a ver si malicio en vano!

Al punto que te despiertas

y yo a escondidas te miro...

lo primero es un suspiro

que casi a exhalar no aciertas.

Te levantas mientras tanto

y vas con Beatriz a misa... 
tu oración no empieza en risa...

pero siempre acaba en llanto!

Vuelves con los ojos rojos

y que yo los miro ignoras...

Cuanto más pasan las horas

más se enrojecen tus ojos.

Vas al huerto; de sus plantas

y de sus encantos gustas,

si alguien te llama te asustas,

y si te miran te espantas...

y así por docenas de versos más. La madurez de la niña no convence, especialmente cuando chantajea a María al revelar que ella (Margarita) sabe que las miradas de María «van / en pos de ese capitán, / que solo te dio un suspiro...». Otro fallo es el cambio abrupto en la actitud de D. Diego para con María. Diego, que había recogido a María 12 años atrás cuando se encontró abandonada (se describe como una «flor» solitaria), sin conocer ni a su padre ni a su madre. Pero de repente, Diego la abraza y declara, « Ya no soy tu bienhechor, / soy sostén de tu virtud ... / yo no quiero gratitud ... / yo necesito tu amor!» (I, 9), un cambio que el dramaturgo no prepara con la debida sutileza.

A pesar de dichos fallos, otros elementos -tema, escenario, iluminación- forman parte del espectáculo que tanto gustó al público. La tensión con que acaba el segundo acto (D. Diego se da cuenta de que conoció al padre de D. Gonzalo en la guerra y que éste deshonró a la familia), que lleva a unas amenazas (¿se harán daño?) y, por fin, a la «oración de la tarde» de Margarita, está bien estructurada y es convincente. Eso, junto con las excelentes intervenciones de dos de los grandes actores madrileños de la época -Teodora Lamadrid (en el papel de María) y Julián Romea (en el papel de D. Diego de Mendoza)- y la fluidez de la versificación (la mayor parte en rima asonantada ${ }^{8}$ ), aseguraron su éxito.

8. Buen ejemplo son los versos que recita D. Gonzalo después de confirmar su amor por María: «Bien hayas, noche apacible! / ¡noche serena, bien hayas! / Ya tu luz no saldrá nunca / para alumbrar la desgracias, / ya en su corazón de ángel / el sol verterá sus galas, / y a los rayos de su lumbre / se abrirá feliz su alma. / Tú, menos triste que sueles, / luna bella, y menos pálida, / has protegido esta noche / mi amor y mis esperanzas! / Tú, noche tranquila, has sido / la aurora de un bien que avanza: / ¡bien hayas, noche apacible! / ¡noche sereena, bien hayas!» (II, 7). Para Calvo Asensio la obra es de «acabada y poética inspiración, tan feliz en el fondo como en la forma» (131). Continúa Calvo: «Unas veces es enérgico y grandilocuente, otras festivo y ameno, así calza el coturno como el zueco, y su fluida y vivaz versificación lo mismo se adapta a las tempestades del drama, que a los discreteos de la comedia clásica, y a las graciosas malignidades de la sátira moderna. Este es el poeta» (131). 
Sin embargo, La oración de la tarde provocó un escándalo. El crítico (y confesado amigo de Larra) Manuel del Palacio, publica en La Discusión (23 de diciembre de 1858) una reseña en la que reconoce la gran popularidad que ha alcanzado la obra, aunque cuestiona su originalidad, acusándole incluso de plagio de una obra titulada El cura de la aldea de Enrique Pérez Escrich. La acusación se tomó tan en serio que un tribunal, compuesto por los dramaturgos Tomás Rodríguez Rubí, Juan Eugenio Hartzenbusch, Juan de la Rosa González y Narciso Serra, fue nombrado para juzgar la originalidad de la obra de Larra. Los cuatro autores no sólo leyeron las dos obras sino que entrevistaron a los dos dramaturgos. Su juicio de esta «delicada y espinosa» situación se publicó en La Iberia el 2 de enero de 1859. Comentando la «ruidosa cuestión» provocada por la obra de Larra, los jueces concluyeron:

\begin{abstract}
Nosotros los abajo firmantes, nombrados para decidir acerca de la originalidad respectiva de los dos dramas La oración de la tarde y El cura de la aldea, creemos y decimos, según nuestro leal saber y entender, que ambas obras son entre sí distintas en la disposición del plan, en los caracteres y principales incidentes, aunque así en la una como en la otra, se usa de un mismo recurso dramático para producir el deseado enlace; recurso que ambos autores han podido muy bien emplear sin tomarlo el uno del otro, como consecuencia de la índole y del objeto moral en que las dos obras asímismo convienen.
\end{abstract}

En la misma página, La Iberia indica que «esta bella producción ha valido a su autor honra y provecho.» Incluso Palacio, a pesar de las duras críticas que emite sobre la obra de Larra, confiesa que:

\begin{abstract}
Debemos, a pesar de todo, confesar que desde la mitad del acto segundo hasta la conclusión del drama, el interés aumenta progresivamente, y que el colorido que ha dado a la obra y la elevación del carácter que ha impreso a todos los personajes, acreditan al señor Larra y hacen de la Oración de la tarde una producción que será siempre escuchada con gusto y aplaudida con entusiasmo (La Época 29 de enero de 1859).
\end{abstract}

Pero el crítico no le perdona varios defectos literarios que, por ser «hijo de Fígaro,» debería haber podido evitar, por no decir nada de varias «vulgaridades» que existen, según Palacio, porque el autor escribió la obra «precipitadamente.» Y La oración siguió provocando escándalo un mes más tarde. Según La Época, de la misma fecha de la reseña de Palacio (29 enero 1859), un individuo que silbó la representación del 28 de enero fue expulsado del teatro por las autoridades. «¿Es un delito silbar? ¿Lo es el aplaudir? ¡A este extremo podíamos llegar,» comenta indignadamente el autor de la crítica. Diez años más tarde Romea sigue ganando aplausos 
en el papel de D. Diego en «uno de los dramas más aplaudidos de nuestro moderno repertorio y el que más ha contribuido a formar la reputación de que goza el señor Larra, su autor» (La Iberia 9 de octubre de 1859). Tuvo tanto éxito esta comedia de Larra que ya durante años la prensa le llamaba sencillamente «el aplaudido autor de La oración de la tarde» (por ejemplo, en la ocasión de la concesión de la Cruz de Isabel la Católica comentada en La Época 19 de diciembre de 1872).

Larra se reveló sensible a la crítica negativa que suscitó su obra, especialmente a la acusación de facilidad o rapidez de su producción. En 1875 Calvo Asensio habla de la «estrema facilidad,» de la «precipitación y descuido» con que escribe, lo que ocasiona que

Los caractéres no están por completo descritos, sino a la ligera diseñados; la acción no se desarrolla en toda la plenitud de la idea a que obedece, antes resulta apenas indicada; generalmente el desenlace se precipita, como si obedeciera a cansancio del poeta... (129)

Luego, en la Revista Financiera y Literaria aparece otra observación parecida, pero Larra se defiende en el citado artículo de 1882 («La situación del autor dramático»), donde escribe:

... he escrito noventa obras dramáticas en treinta años, cosa que no debe asustar a nadie, pues nadie se asusta, y con razón, de que un pintor pinte tres cuadros, un médico haga tres operaciones difíciles, un abogado defienda tres pleitos de importancia o un arquitecto construya tres casas en un año, trabajando, como yo lo hago, cinco horas al día; yo, por último, para poder vivir, no en la opulencia, sino desahogadamente, he abordado todos los géneros en el teatro y he visto coronadas muchas de mis obras por éxitos de sesenta a cien representaciones consecutivas que aquí se tienen por fabulosas; yo, por fin, humilde autor que con varios de mis dramas, comedias y zarzuelas, no he dejado de proporcionar algunos millones a las empresas teatrales ...

Así defiende su popularidad, su riqueza, su talento, su decisión de no ser un «autor serio»: hay muchos, dice, que han intentado escribir obras exitosas, pero pocos han triunfado como él.

A pesar de la crítica negativa que recibe y los fallos que uno detecta en sus obras, se ve con claridad que ese «desconocido» Larra (en su época nada desconocido, como hemos visto) fue un autor dotado de un marcado talento dramático. No fue un dramaturgo sin controversia, ${ }^{9}$ pero ganó

9. Por ejemplo, La Iberia publica una crítica de La planta exótica (1857-XII-19) en la que le acusa de escribir una obra «hipócritamente inmoral.» He aquí el texto de la crítica: «Anoche se estrenó en 
cuantiosas sumas por sus obras y vivió bien de esas ganancias. Cayó en el olvido, pero quizás inmerecidamente. Ya es hora de rescatar de ese olvido y devolver a un puesto de digno recuerdo en la dramaturgia del siglo XIX español al autor de El barberillo de Lavapiés.

el Circo la comedia de este título, en tres actos y en verso, debida a la pluma del joven poeta don Luis Mariano de Larra. No hemos visto nada más hipócritamente inmoral que esta comedia, en que se retrata el vicio con los más vivos colores, para después dejarle salir triunfante; porque pretender moralizar, como al parecer se ha propuesto hacerlo el señor Larra, presentando la misma inmoralidad, retratada con refinamiento en Rosalía, es lo mismo que inocular en el alma el virus corrosivo, para decir después con aire satisfecho: esto mata. Una pregunta al señor Larra: Si el tipo de la mujer prostituida de alma y de cuerpo no existe en España, como nosotros queremos creer, ¿por qué nos la presenta en escena? ¿Ignora el autor de La planta exótica que hay armas tan peligrosas que hieren al que las maneja? ¿Qué castigo tiene en la comedia del señor Larra esa especie de Dalila o Traviata que nos ha presentado? ¿El desprecio de las personas honradas que al conocer sus vicios se horrorizan de ellos? No faltaba más que no sucediera así. ¿Pero esto es por fortuna bastante castigo para esas mujeres sin alma y sin sentimientos cristianos que, después de ser conocidas de las personas de quienes se han burlado, sueltan como la protagonista de la comedia del señor Larra, uan carcajada satánica, y huyen de ellas seguras de encontrar otras familias en donde ejercer su influencia fatal? Nosotros creemos que no, y que lo mejor que puede hacerse es no presentar ese peligroso tipo en la escena, ya que para desgracia de la sociedad existe en el mundo. En la parte escrita ha rayado el autor de La planta exótica a mucha altura, dándonos admirablemente versificadas dos escenas de primer orden: la del general y Ricardo en el acto segundo, y la de Rosalía y el general en el tercero. El éxito de esta comedia no ha pasado de mediano, habiendo sido llamado el autor a la escena a su conclusión por los espectadores de las galerías. La ejecución fue admirable. Teodora [Lamadrid] desplegó todos los encantos de la gracia y de la seducción, y consiguió que los espectadores la aplaudieran precisamente en la escena en que representando el cinismo se burla de la virtud. Aquellos aplausos eran a la actriz, bien lo sabemos; pero así y todo resonaron en nuestros oidos de una manera fatídica. El señor [Julián] Romea, inimitable en su papel de general anciano: nosotros al verle con aquella peluca blanca nos lisonjeamos, porque comprendimos los legítimos triunfos que le esperan en la nueva fase de su gloriosa carrera artística. Rosa.» 


\section{BIBLIOGRAFÍA}

Calvo Asensio, G. El teatro hispano-lusitano en el siglo XIX, Madrid, Rojas, 1875 [Repr. Madrid: Elibron Classics, 2006].

Fundación Juan March, Catálogo de obras de teatro español del siglo XIX. Madrid: Fundación Juan March, 1986.

Encina Cortizo, María y Ramón Sobrino, eds., Francisco Asenjo Barbieri, El barberillo de Lavapiés, zarzuela en tres actos con libreto de Luis Mariano de Larra, Madrid, Instituto Complutense de Ciencias Musicales, 1994.

Espín TemPlado, María Pilar, El teatro por horas en Madrid (1870-1910). Madrid, Instituto de Estudios Madrileños, 1995.

Gies, David T., «La generación de 1850: Narciso Serra, Luis de Eguílaz y Luis Mariano de Larra», en El teatro en la España del siglo XIX, Cambridge, CUP, 1996, pp. 364-394.

González Subías, José Luis, Catálogo de estudios sobre el teatro romántico español y sus autores. Fuentes bibliográficas, Madrid, FUE, 2005.

Historia del teatro español, ed. Javier Huerta Calvo, 2 vols., Madrid, Gredos, 2003.

LARRA, Luis Mariano de, La oración de la tarde, drama en tres actos y en verso, original de ... Madrid, José Rodríguez, 1858.

-. Una virgen de Murillo, comedia original, en tres actos y en verso, por D. Luis de Eguílaz y ... Madrid, José Rodríguez, 1854.

ReEs, M.A., The Nineteenth-Century Theatre in Spain. A Bibliography of Criticism and Documentation, Bulletin of Hispanic Studies, 78 (2001) (supplement).

Revilla, Manuel de la, «Crónica dramático-musical. El barberillo de Lavapiés, zarzuela en tres actos. Letra de D. Luis Mariano de Larra» La Crítica (Madrid). 24 Diciembre 1874.

Rogers, Paul Patrick, The Spanish Drama Collectionn in the Oberlin College Library, Oberlin, OH, Oberlin College, 1940.

Vallejo, Irene y Pedro Ojeda, El teatro en Madrid a mediados del siglo XIX. Cartelera teatral (1854-1964), Valladolid, U. de Valladolid, 2001.

Veinticuatro Diarios. Madrid, 1830-1900. 4 tomos, Madrid, CSIC, 1968-1975. 
APÉNDICE: Obras dramáticas de Luis Mariano de Larra (1830-1901)

A caza de cuervos (comedia arreglada del francés, 1854; en colaboración con José María de Larrea)

La africanita (zarzuela, 1886)

La agonía (juguete dramático, 1861)

La agonía de Colón (juguete dramático, sf)

El amor y el interés (comedia, 1857)

El amor y la moda (comedia, 1852)

El ángel de la muerte (drama fantástico arreglado del francés, 1868)

El año de la Nanita (zarzuela cómica, 1886)

¡Apunten! ifuego! (1888)

El árbol del paraíso (comedia, 1870)

As en puerta (zarzuela, 1855)

El atrevido en la corte (zarzuela, 1872)

El barberillo de Lavapiés (zarzuela, 1874)

Barómetro conyugal (comedia, 1859; en colaboración con Ventura de la Vega)

Batalla de reinas (comedia, 1856; en colaboración con Isidoro Gil)

El becerro de oro (comedia, 1869)

El beso de Judas (comedia, 1855)

El bien perdido (comedia, 1866)

¡Bienaventurados los que lloran! (comedia, 1866)

Boccaccio (zarzuela, 1882)

La bolsa y el bolsillo (comedia, 1859; en colaboración con Ventura de la Vega)

El caballero de Gracia (drama tradicional, 1871)

Cadenas de oro (zarzuela, 1864; en colaboración con Ramón de Navarrete)

Las campanas de Carrión (zarzuela, 1888)

Chorizos y Polacos (zarzuela, 1876)

El conde y el condenado (zarzuela, 1874; en colaboración con Antonio García Gutiérrez)

La conquista de Madrid (zarzuela, 1863)

Los corazones de oro (comedia, 1875)

La cosecha (comedia, 1863)

El cuello de una camisa (comedia, 1852; en colaboración con Cayetano de Suricalday)

¡Dios sobre todo! (comedia, 1862)

El embuste y una boda (sf)

En brazos de la muerte (drama, 1866) 
En palacio y en la calle (drama, 1853)

El entreacto (1888)

Entre todas las mujeres (comedia, 1854; en colaboración con Luis de Eguílaz)

Estudio del natural (drama, 1863)

La flor del valle (drama, 1856)

Flores y perlas (drama, 1860)

La gala del Ebro (zarzuela, 1886)

La guerra santa (zarzuela, 1879; en colaboración con Enrique Pérez Escrich)

Las hijas de Eva (zarzuela, 1862)

Los hijos de Adán (juguete cómico, 1869)

Los hijos de la costa (zarzuela, 1871)

Los hijos de Madrid (zarzuela melodramática, 1881)

El hombre libre (comedia, 1862)

Los infieles (juguete cómico, 1860; en colaboración con Narciso Serra)

Los infiernos de Madrid (zarzuela fantástica, 1867)

La ínsula Barataria (zarzuela, 1864)

Juan de Urbina (zarzuela, 1876)

Juicios de Dios (drama, 1856)

Justos por pecadores (zarzuela, 1871)

Lanuza (drama, 1854)

La lápida mortuoria (traducción de Dumas, 1859)

Los lazos de la familia (drama, 1859)

Manolito el Rayo (opereta cómica, 1886; en colaboración con Antonio Llanos)

El marqués y el marquesito (traducción de Bayard, 1859)

Los misterios del Parnaso (revista crítica, 1868)

¡Muchacho! (sainete cómico-lírico, 1885)

La niña bonita (zarzuela, 1881)

¡Ojo y nariz! (disparate cómico, imitación de una comedia francesa de Paul de Kock, 1850; en colaboración con Ramón de Valladares y Saavedra)

La oración de la tarde (drama, 1858)

Los órganos de Móstoles (zarzuela bufa, 1867)

Oros, copas, espadas y bastos (juguete cómico, 1866)

Los pajes del rey (zarzuela, 1876)

La paloma y los halcones (comedia, 1857)

Pedro el marino (comedia arreglada del francés, 1852)

Perder la pista (1888)

La perla negra (zarzuela, 1858)

La planta exótica (comedia, 1857) 
La pluma y la espada (drama, 1856)

La primera piedra (drama, 1862)

La prima donna (juguete cómico, 1872)

Punto y aparte (zarzuela, 1865)

Quien a cuchillo mata (comedia arreglada del francés, 1853; en colaboración con José María de Larrea)

Quien piensa mal, mal acierta (comedia, 1851; en colaboración con Juan Catalina)

Las ranas pidiendo rey (fábula, 1881)

El rey del mundo (comedia, 1858)

¡Rico - de amor! (comedia, 1859)

¡Risas y lágrimas! (drama, 1878)

Sapos y culebras (sf; en colaboración con Luis de Eguílaz)

Septiembre, Eslava y compañía (1888)

Sueños de oro (zarzuela fantástica, 1872)

La tarde de Noche-buena (escenas cómicas, 1871)

Todos son raptos (zarzuela, 1851)

El toro y el tigre (disparatado apropósito, 1849; en colaboración con Ramón de Valladares y Saavedra)

Las tres noblezas (comedia, 1853)

Tres pies al gato (comedia, 1876)

Un buen hombre (1884)

Un embuste y una boda (zarzuela, 1851)

¡Una lágrima! (boceto dramático, 1874)

Una lágrima y un beso (comedia, 1855)

Una nube de verano (comedia, 1854)

Una revancha (zarzuela, 1864)

Una virgen de Murillo (comedia, 1854; en colaboración con Luis de Eguílaz)

La varita de virtudes (zarzuela de magia, 1868)

El viaje a la luna (1876)

La viuda de López (comedia, 1884)

La vuelta al mundo (viaje inverosímil, 1875) 